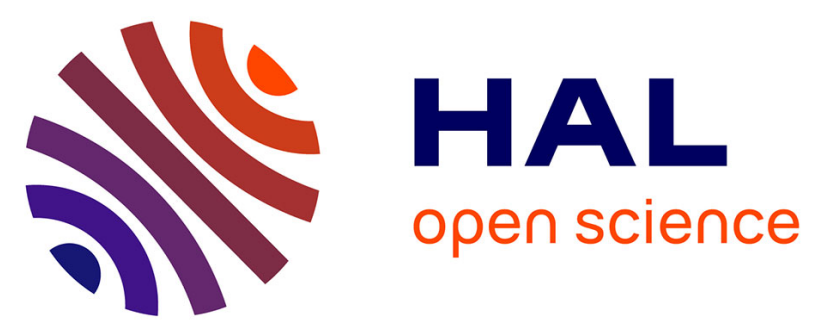

\title{
Contribution to the MHD modeling in low speed radial flux AC machines with air-gaps filled with conductive fluids
}

Hocine Menana, Jean-Frederic Charpentier, Celine Gabillet

\section{To cite this version:}

Hocine Menana, Jean-Frederic Charpentier, Celine Gabillet. Contribution to the MHD modeling in low speed radial flux AC machines with air-gaps filled with conductive fluids. IEEE Transactions on Magnetics, 2014, 50 (1), pp.1-4. 10.1109/TMAG.2013.2281421 . hal-01072163

\section{HAL Id: hal-01072163 \\ https://hal.science/hal-01072163}

Submitted on 7 Oct 2014

HAL is a multi-disciplinary open access archive for the deposit and dissemination of scientific research documents, whether they are published or not. The documents may come from teaching and research institutions in France or abroad, or from public or private research centers.
L'archive ouverte pluridisciplinaire $\mathbf{H A L}$, est destinée au dépôt et à la diffusion de documents scientifiques de niveau recherche, publiés ou non, émanant des établissements d'enseignement et de recherche français ou étrangers, des laboratoires publics ou privés. 


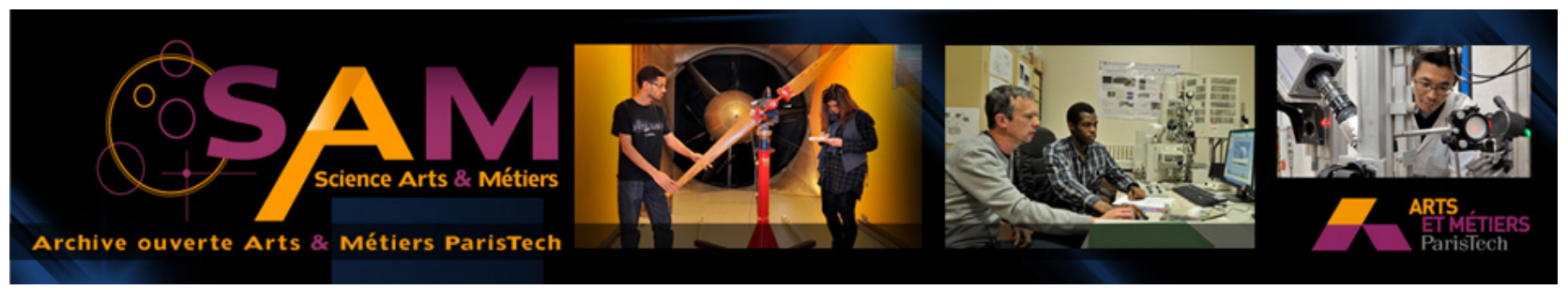

\section{Science Arts \& Métiers (SAM)}

is an open access repository that collects the work of Arts et Métiers ParisTech researchers and makes it freely available over the web where possible.

This is an author-deposited version published in: http://sam.ensam.eu

Handle ID: .http://hdl.handle.net/10985/8702

\section{To cite this version :}

Hocine MENANA, Jean-Frederic CHARPENTIER, Celine GABILLET - Contribution to the MHD modeling in low speed radial flux AC machines with air-gaps filled with conductive fluids - IEEE TRANSACTIONS ON MAGNETICS - Vol. 50, n¹, p.1-4 - 2014 


\title{
Contribution to the MHD Modeling in Low Speed Radial Flux AC Machines With Air-Gaps Filled With Conductive Fluids
}

\author{
H. Menana, J. F. Charpentier, and C. Gabillet \\ Research Institute of the French Naval Academy (IRENav), CC 600, 29240, Brest Cedex 9, France
}

\begin{abstract}
This work deals with the modeling of the magnetohydrodynamic (MHD) phenomena in the air-gaps of low speed radial flux AC electrical machines filled with incompressible and electrically conductive fluids. The proposed model concerns laminar flows and it is based on a weak MHD coupling at the steady state regimes. The MHD power losses are evaluated and discussed. The model is easy to implement and could be a useful tool for the design and the optimization. An application to marine current turbine is considered.
\end{abstract}

Index Terms-Analytical modeling, fluid-filled air-gaps, laminar flows, low speed radial flux AC machines, MHD, power loss.

\section{INTRODUCTION}

$\mathbf{S}$ OME specific applications use immersed air-gap $\mathrm{AC}$ electrical machines. These applications can be related with renewable marine energy [1], specific pumping systems [2] and air-gap reluctivity elimination by magnetic fluids [3]. The airgaps of these electrical machines can be filled with conductive fluids (seawater...) which induces MHD phenomena due to the rotating magnetic field densities (MFDs), leading to supplementary losses and flow distortion in the air-gap. These nonconventional phenomena are often neglected in the design and the modeling procedures of such systems. It is however necessary to quantify these phenomena to check if they are insignificant, especially when high MFDs are involved, such as in superconducting electrical machines.

A rigorous modeling of the MHD phenomena may be a challenging problem leading to heavy numerical models [4][5]. These numerical models are not suitable to be used for the design, where rapid models are needed [6]. In this context, and under the assumption of laminar incompressible fluid flows, we present an analytical modeling of the MHD phenomena in the air-gaps of low speed radial flux AC electrical machines filled with electrically conductive fluids. It is based on a weak MHD coupling in the steady state regimes and assumes a sinusoidal distribution of the MFDs in the air-gap. The effect of the rotating magnetic field on the fluid flow in the air-gap is discussed and the MHD losses are evaluated. The model is easy to implement and could be a useful tool for the design and the optimization.

The study of the flow stability is out of the scope of this work. We assume that the considered systems work below the critical Taylor number determining the transition from laminar to transitional the flow of a viscous fluid between two concentric cylinders [7]-[9].

The modeled system and the MHD model equations are presented in the next section. Results and discussions are given in the third section considering an application to a marine current turbine. We don't aim any particular application, thus the dimensions of the considered machine are arbitrary chosen,

Manuscript received November 30, 2012; revised May 04, 2013; accepted September 07, 2013. Date of publication September 11, 2013; date of current version December 23, 2013. Corresponding author: I1. Menana (e-mail: hocine. menana (a ceole-navale.fr). nevertheless realistic and satisfying the condition of a laminar flow.

\section{THE MHD MODEL}

Using cylindrical coordinates $(r, \theta, z)$, we consider a simusoidal rotating MFD oriented in the radial direction $\left(B=\left\{B_{r}, 0,0\right\}\right)$ in the mechanical air-gap (magnetic air-gap less any nonmagnetic insulating layer thickness) of a synchronous electrical machine, filled with an incompressible and electrically conductive fluid (Fig. 1). The MFD rotates at the rotor speed $\Omega=\omega / p$, where $\omega$ is the pulsation of the supply currents, and $p$ is the number of poles pairs of the MFD.

\section{A. The MDH Model}

We neglect the end effects; the system is thus azimuthally symmetric. The fluid flows in the air-gap in the azimuthal direction, with the angular speed $\Omega_{f}(r)$ which is considered to depend only on the radial position $r$ (laminar flow). The expression of the MFD in the reference frame of the fluid is given by (1), where $B_{m}$ is the MFD magnitude and $\theta$ is the angular position

$$
B_{r}(r, \theta, t)=B_{m} \sin \left(p\left[\Omega-\Omega_{f}(r)\right] t-p \theta\right) .
$$

The variation of the MFD in the conductive fluid gives rise to an induced electric field $E$ and thus an induced current density $J$. As described in Fig. 1, we assume that the electric field and the induced current density have only one component oriented in the z-direction $\left(E=\left\{0,0, E_{z}\right\}, J=\left\{0,0, J_{z}\right\}\right)$ and the MFD created by the induced current is negligible compared to the MFD magnitude $B_{m}[10]$. From the Maxwell-Faraday's law, and with the notation $\left(\partial_{x} y=\partial y / \partial x\right)$, we have

$$
r^{-1} \dot{\partial}_{\theta} E_{z}=-\dot{\partial}_{t} B_{r} \rightarrow \dot{\partial} E_{z}=-r \dot{\partial}_{t} \theta \partial B_{r} .
$$

In the steady state regime $\partial_{t} \Omega_{f}=0$, thus $\dot{\partial}_{t} \theta=\Omega-\Omega_{f}$, and (2) becomes

$$
E_{z}=(u-r \Omega) B_{r}
$$

where $u=r \Omega_{f}$ is the azimuthal fluid velocity.

The induced current density in the fluid is given by (4), where $\sigma$ is the electrical conductivity of the fluid

$$
J_{z}=\sigma E_{z}=\sigma(u-r \Omega) B_{r} .
$$




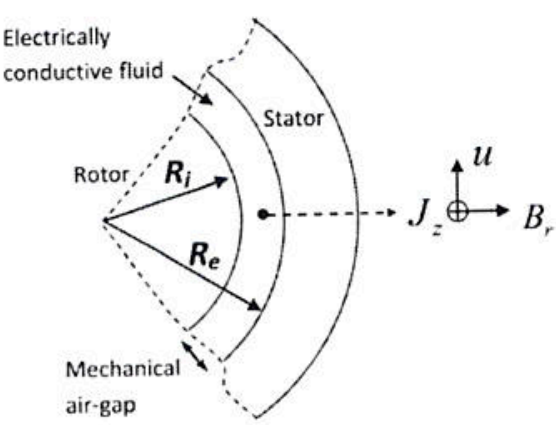

Fig. 1. The modeled system.

As consequence of the induced current, Lorentz forces are induced in the fluid, and oriented in the direction of the fluid flow $(\theta)$. The induced Lorentz forces in the fluid are expressed as follows:

$$
\begin{aligned}
F_{\theta} & =-J_{z} B_{r} \\
& =\sigma(r \Omega-u) B_{m}^{2} \sin ^{2}\left(p\left[\Omega-r^{-1} u\right] t-p \theta\right) .
\end{aligned}
$$

Only the mean value $\left\langle F_{\theta}\right\rangle$ of this force is considered [2]:

$$
\left\langle F_{\theta}\right\rangle=0 . \check{\sigma} \sigma(r \Omega-u) B_{m}^{2} .
$$

The induced Lorentz forces affect the fluid flow. As it is a laminar flow, and due to the symmetry of the system, we consider that the fluid velocity varies only in the radial direction; thus, the variation of the azimuthal velocity $u$ and the pressure $P$ according to the azimuthal coordinate $\theta$ are nil (i.e., $\partial_{\theta} u=0$ and $\left.\partial_{\theta} P=0\right)$ in the Navier-Stokes equation [5], [7]- [9]. The governing MHD equation in the steady state regime $\left(\partial_{t}=0\right)$ is thus reduced to (7), where $\mu$ is the dynamic viscosity of the fluid, and with the notation $\partial_{r}^{2} u \equiv \partial^{2} u / \partial r^{2}$

$$
\partial_{r}^{2} u+r^{-1} \partial_{r} u-r^{-2} u=-\mu^{-1} F_{\theta} .
$$

We consider only the mean value of the Lorentz force (6). With $\lambda=\sqrt{0.5 \sigma B_{m}^{2} \mu^{-1}},(8)$ becomes

$$
\partial_{r}^{2} u+r^{-1} \partial_{r} u-\left(r^{-2}+\lambda^{2}\right) u=-\lambda^{2} r \Omega .
$$

Notice that in the case of ferrofluids, it is the magnetic forces that occur rather than the Lorentz forces [4].

The solution of (8) is given in (9), expressed in terms of the first order modified Bessel functions of the first kind $I_{1}($.$) , and$ second kind $K_{1}($.

$$
u=A I_{1}(\lambda r)+B K_{1}(\lambda r)+r \Omega .
$$

The constants $A$ and $B$ are determined by the boundary conditions of the velocity on the rotor outer radius $R_{i}$ and the stator inner radius $R_{e}$. The no-slip boundary conditions applies [5], [7]-[9], thus we have

$$
\left\{\begin{array}{ll}
u=R_{i} \Omega & \left(r=R_{i}\right) \\
u=0 & \left(r=R_{e}\right)
\end{array} .\right.
$$

Under these boundary conditions and with $\alpha=\lambda R_{i}$ and $\beta=$ $\lambda R_{e}$, we obtain

$$
\left\{\begin{array}{l}
A=\Omega R_{e} K_{1}(\alpha)\left[K_{1}(\alpha) I_{1}(\beta)+K_{1}(\beta) I_{1}(\alpha)\right]^{-1} \\
B=-\Omega 2 R_{r} I_{1}(\alpha)\left[K_{1}(\alpha) I_{1}(\beta)+K_{1}(\beta) I_{1}(\alpha)\right]^{-1}
\end{array} .\right.
$$

Notice that when no magnetic field is applied, the fluid velocity is the homogeneous solution $\left(u_{0}\right)$ of $(7)$ [8][9]. Considering the boundary conditions (11), and with $\eta=R_{i} / R_{e}$, we have

$$
u_{0}=\Omega\left(\eta^{2}-1\right)^{-1}\left(\eta^{2} r-R_{i}^{2} r^{-1}\right)
$$

\section{B. Evaluation of the MHD Losses}

The different MHD power in the air-gap are the electrical power dissipated by the Joule effect (Joule losses) in the fluid $\left(P_{J}\right)$, the electromechanical power transmitted to the fluid by the Lorentz forces $\left(P_{c m}\right)$, and the friction power $\left(P_{\mu}\right)$ due to the fluid viscosity which creates skin friction shear stress on the rotor and stator surfaces [7]-[9]. The latter represents the hydrodynamic power transmitted to the fluid and dissipated by the fluid flow and thermal effect due to the friction between the fluid particles [9]. Since the fluid velocity is nil on the stator surface, no friction power loss occur in the latter.

The Joule losses in the fluid can be expressed as follows, where $L$ is the axial length of the mechanical air-gap and $E_{i e f f}$ is the RMS value of the electric field (the minus sign denotes a loss, and $G V$ denotes the mechanical air-gap volume):

$$
P_{J}=-\sigma \int_{G V} E_{e f f}^{2} d v=-\sigma B_{m}^{2} \pi L \int_{R_{i}}^{R_{c}}(u-r \Omega)^{2} r d r
$$

Considering only the mean value of the Lorentz forces, the electromechanical power is calculated as follows:

$$
P_{c m}=\int_{G V}\left\langle F_{\theta}\right\rangle u d v=-\sigma B_{m}^{2} \pi L \int_{R_{s}}^{R_{e}}(u-r \Omega) u r d r .
$$

As it is a post processing operation, one can solve the integrals (13) and (14) numerically.

Finally, the friction power on the rotor surface is proportional to the derivative of the velocity with respect to the radial direction [7]-[9]. It is calculated as follows, where $I_{0}($.$) and K_{0}($. are the zero order first and second kind modified Bessel functions, $\alpha=\lambda R_{i}$ and $R S$ denotes the rotor surface:

$$
\begin{aligned}
P_{\mu} & =\int_{R S} \mu u\left(R_{i}\right)\left(\partial_{r} u-r^{-1} u\right)_{r=R_{i}} d s \\
& =2 \pi \mu L R_{i}^{2} \Omega\left\{\begin{array}{l}
A \lambda\left[I_{0}(\alpha)-\alpha^{-1} I_{1}(\alpha)\right]- \\
B \lambda\left[K_{0}(\alpha)+\alpha^{-1} K_{1}(\alpha)\right]
\end{array}\right\} .
\end{aligned}
$$

Replacing in (15) $u$ by $\Delta u=u-u_{0}$, we obtain the variation of the friction power loss $\Delta P_{\mu}$ on the rotor surface due to the application of the magnetic field, given by $(16)$, where $P_{\mu}^{0}$ is the friction loss when no magnetic field is applied:

$$
\Delta P_{\mu}=P_{\mu}-P_{\mu}^{0}=P_{\mu}-4 \pi \mu L R_{i}^{2} \Omega^{2}\left(\eta^{2}-1\right)^{1} .
$$


TABLE I

PARAmeters Specific ation

\begin{tabular}{lll}
\hline \hline Parameters & \multicolumn{2}{l}{ Values } \\
\hline Inner radius, $R_{i}$ & 1 & $\mathrm{~m}$ \\
Outer radius, $R_{c}$ & $1.001 \mathrm{~m}$ \\
Axial length, $L$ & 1.5 & $\mathrm{~m}$ \\
Rotor speed, $\Omega \quad f=50 \mathrm{~Hz}, p=250)$ & $0.4 \pi \quad \mathrm{Rad} / \mathrm{s}$ \\
Fluid conductivity. $\sigma$ & 5 & $\mathrm{~S} / \mathrm{m}$ \\
Fluid density, $\rho$ & $10^{3}$ & $\mathrm{Kg} / \mathrm{m}^{3}$ \\
Fluid dynamic viscosity, $\mu$ & $10^{-3} \quad \mathrm{~Pa} . \mathrm{s}$ \\
Taylor number. $T n$ & $1579 \mathrm{H}$ \\
MFD free friction loss, $P_{\mu}^{0}$ & $-14.9 \mathrm{~W}$ \\
\hline \hline
\end{tabular}

It is a gain in power which is nearly equal to the electromechanical power transmitted to the fluid $\left(\left|\Delta P_{\mu}\right| \approx\left|P_{r+m}\right|\right)$, as long as the losses due to the friction between the fluid particles can be neglected. Indeed, the Lorentz forces tend to accelerate the fluid in the direction of the rotor motion to minimize the eddy currents, leading to a decrease of the term $\partial_{r} u$ in (15), and thus a compensation of a part of the friction power on the rotor surface.

\section{APPLICATION}

\section{A. The System Specifications}

An example of a POD PM generator for a marine current turbine is used to illustrate the MHD phenomena presented above. The chosen set of dimensions corresponds to a rough design of a $450 \mathrm{~kW} / 12 \mathrm{rpm}$ generator which corresponds approximately to the specifications of a $15 \mathrm{~m}$ diameter tidal turbine designed for a rated water velocity of $2.3 \mathrm{~m} / \mathrm{s}$. These specifications are close to those of major current industrial marine current turbine projects which have been tested at sea in the last years, as the OPENHYDRO project (http://www.openhydro.com) or Seagen/Seaflow projects (http://www.seageneration.co.uk). The chosen rated velocity is typical of high potential tidal sites located near the west European shorelines [1]. The corresponding set of parameters is presented in Table I. These parameters satisfy the condition of a laminar flow, which is verified by the evaluation of the Taylor number $T n=R_{i}\left(R_{c}-R_{i}\right)^{3} \mu^{-2} \rho^{2} \Omega^{2}$ [7], [8], where, in this case, $R_{i}$ is the rotor outer radius, $R_{e}$ is the stator inner radius (including the insulations thicknesses), $\Omega$ is the rotor speed, $\mu$ is the dynamic viscosity and $\rho$ is the density of the fluid. It must be less than its critical value of about 1700 [8].

\section{B. Results and Discussions}

The MHD model is implemented in Matlab environment. The integrals (13) and (14) are evaluated numerically by using the trapezoidal numerical integration method.

The radial profile of the eddy currents amplitude is given by Fig. 2 for different values of the MFD. The mean values of the Lorentz forces have a similar distribution. The eddy currents are nil on the rotor surface where the fluid velocity is the same as that of the rotating magnetic field. The eddy currents increase linearly to reach a maximum at the stator surface where the relative velocity of the rotating magnetic field with respect to the fluid is maximal. It is not shown here, but, at high values of the MFD (case of use of superconducting materials for instance),

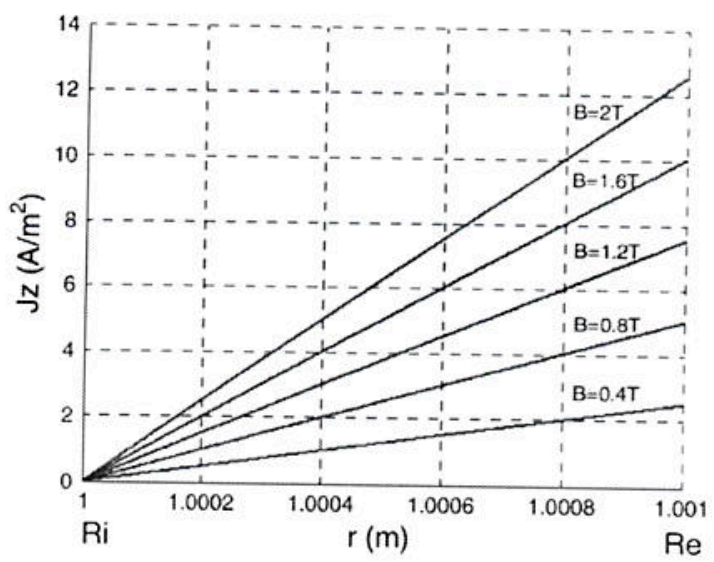

Fig. 2. Radial profile of the eddy currents in the mechanical gap for different values of the magnetic flux density.

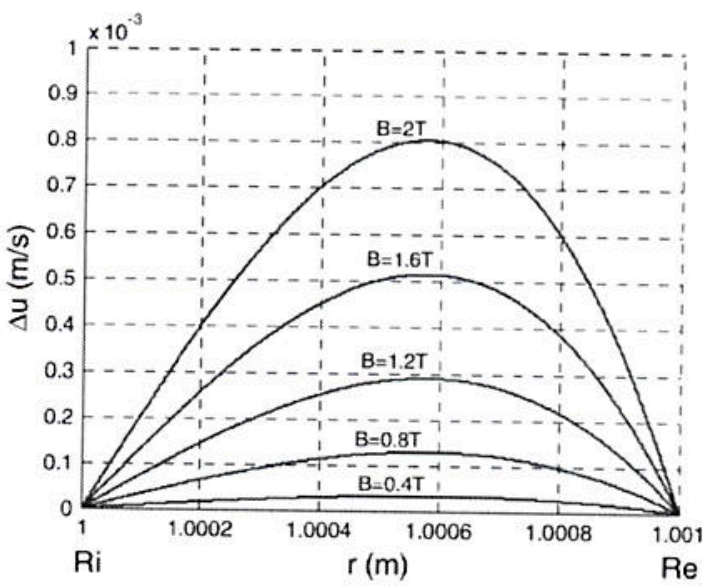

Fig. 3. Radial profile of the fluid velocity variation for different values of the magnetic flux density.

the eddy currents profile is no longer linear in the gap; since, as the MFD increases, the Lorentz forces become more important, and thus the fluid velocity tends to reach that of the rotating magnetic field over a large part of the gap starting from the rotor surface, limiting the zone of the development of the eddy currents to an area close to the stator surface.

The profile of the variation of the fluid velocity $(\Delta u)$ is represented in Fig. 3 for different values of the MFD. Due to the no-slip boundary condition, its maximum does not occur at the stator surface; however it is closer to the stator surface than the rotor surface, which is coherent with the variations of the eddy currents and Lorentz forces. We can also notice that $\Delta u$ varies in a nonlinear way according to the MFD.

Fig. 4 shows the variation of the different MHD powers (gain $\&$ losses) according to the MFD. The gain in the friction power $\left(\Delta P_{\mu}\right)$ is considered positive while the Joule losses and the electromechanical power $\left(P_{. I} \& P_{e m}\right)$ are considered negative. We can see that, as we stated above, $P_{e^{e} m}$ resulting from the numerical integration of (14) is nearly equal to $-\Delta P_{\mu}$ given by (16). There is thus compensation between $P_{e m}$ and $\Delta P_{\mu}$, and therefore, the total MHD loss in the system is nearly equal to the Joule losses $\left(P_{J}\right)$ plus the MFD free friction loss $\left(P_{\mu}^{0}\right)$ given 


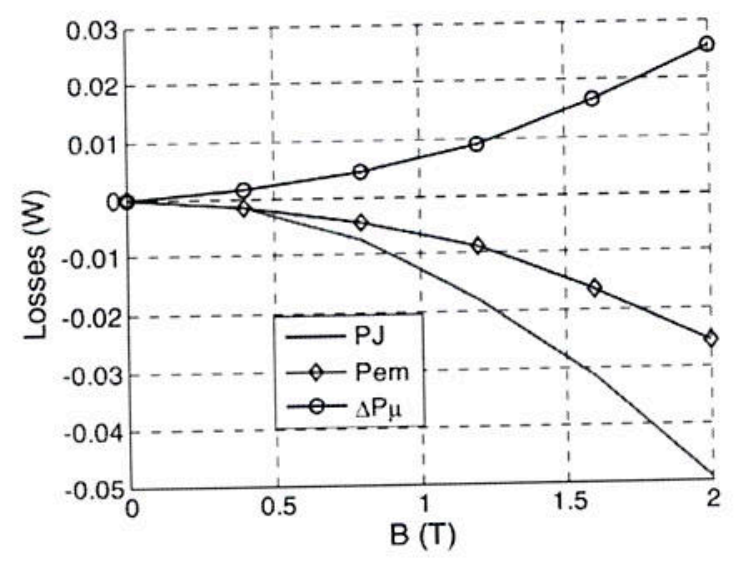

Fig. 4. MHD power losses as function of the magnetic flux density.

in Table I, which is the predominant one. The Joule losses are about twice larger than $P_{\mathrm{em}}$, which is due to the weak conductivity of the fluid. For highly conductive fluids, $P_{\mathrm{em}}$ would be more important than $P_{J}$.

We can notice that according to the considered example, the MHD losses may be negligible compared to the machine power. However, in absolute terms, they are a part of nonconventional losses which deserve to be quantified [11].

\section{CONCLUSION}

We have developed an analytical modeling of the MHD phenomena in the air-gaps of low speed radial flux AC synchronous machines filled with incompressible and electrically conductive fluids. The MHD power losses are evaluated and discussed. The model is easy to implement and could be a useful tool for the design and the optimization, especially when the involved MFDs are important (superconductive machines), or when the air-gap fluids are highly conductive. The model can easily be applied to the asynchronous machines by simply taking into account the slip between the rotor and the rotating MFD.
The proposed model is however limited to laminar flows and based on a weak MHD coupling. Furthermore, it assumes that the MFD distribution is sinusoidal, and only the mean values of the induced Lorentz forces are considered. Further investigations are thus needed to consider the possibility of extending the model to transitional and turbulent flows. It would be also interesting to take into account the effect of the MFD harmonics, and to study the effect of the Lorentz forces and their fluctuation on the stability of the fluids flows; this can affect considerably the hydrodynamic losses which are known to be more important in transitional and turbulent regimes.

\section{REFERENCES}

[1] S. Benelghali, M. E. H. Benbouzid, and J. F. Charpentier, "Marine tidal current electric power generation technology: State of the art and current status," Proc. IEEE IEMDC., Antalya, vol. 2, pp. 1407-1412, 2007.

[2] K. Ueno and T. Ando, "Theoretical study of induction pump for molten metal using rotating twisted magnetic field," IEEE Trans. Magn., vol. 48, no. 3, pp. 1200-1211, Mar. 2012.

[3] A Judge, "Air gap elimination in permanent magnet machines," Ph.D. dissertation, Worcester Polytechnic Institute, Worcester, MA, Mar. 2012.

[4] G. Yoshikawa, K. Hirata, F. Miyasaka, and Y. Okaue, "Numerical analysis of transitional behavior of ferrofluid employing MPS method and FEM," IEEE Trans. Magn., vol. 47, no. 5, pp. 1370-1373, May 2011.

[5] T. W. Berger, J. Kim, C. Lee, and J. Lim, "Turbulent boundary layer control utilizing the Lorentz force," Phys. Fluids, vol. 12, no. 3, pp. 631-649, Mar. 2000.

[6] S. Djebarri I, J. F. Charpentier, F. Scuiller, M. Benbouzid, and S. Guemard, "Rough design of a double-stator axial flux permanent magnet generator for a rim-driven marine current turbine," in Proc. IEEE-ISIE, Hangzhou, May 2012, pp. 1450-1455.

[7] G. I. Taylor, "Stability of viscous liquid contained between two rotating cylinders," Phil. Trans. R. Soc. Lond A., vol. 223, pp. 289-343, 1923.

[8] M. Frank White, Flaid Mechanics, 4th ed. McGraw-Hill [Online]. Available: http://watinst.ut.ac.ir/downloads/pdf/ebooks/white.pdf

[9] H.-S. Dou. B. C. Khoo, and K. S. Yeo, "Energy loss distribution in the plane Couette flow and the Taylor-Couette flow between concentric rotating cylinders," Int. J. Therm. Sci., vol. 46, pp. 262-275, 2007.

[10] M. Werner and B. Halbedel, "Optimization of NdFeB magnet arrays for improvement of Lorentz force velocimetry," IEEE Trans. Magn. vol. 48, no. 11, pp. 2925 2928, Nov. 2012.

[11] J. Vianei Leite, M. V. Ferreira da Luz, N. Sadowski, and P. Armando da Silva, Jr., "Modelling dynamic losses under rotational magnetic flux," IEEE Trans. Magn., vol. 48, no. 2, pp. 895-898, Feb. 2012. 